Although our graft insertion technique requires graft-to-graft anastomosis between the graft anastomosed to the LVOT and the composite graft, this graft-to-graft anastomosis can be easily performed with continuous over-and-over sutures.

The aortic valve allograft is considered one of the best choices for avoiding recurrence of infection in cases of PVE with extensive tissue destruction. However, in addition to the allograft being hard to come by, an irregular suture line of the aortic annulus after aggressive debridement would make the allograft prone to distortion. In such complicated cases our technique should be a good alternative. When resection of the severe root abscess results in a defect of the intervalvular fibrous body, reconstruction through the aortic root and dome of the atrium is mandatory. We believe our technique can be applied together with atrioventricular reconstruction.

Another advantage of our graft insertion technique is that a valve larger than the LVOT can be inserted in patients with small aortic roots. In such a case the graft anastomosed to the LVOT can be cut on the bias to receive a larger stentless valve or composite graft containing a valve larger than the LVOT, whereas without the connecting graft, the composite graft with the valve would have to be the same diameter as the LVOT.
Complete heart block is a common complication after reoperation on the aortic root with a $10 \%$ to $30 \%$ occurrence rate. ${ }^{1,2,4,5}$ We put our mattress sutures at the lower edge of the trace of the previous valve or at a slightly higher position in the membranous septum compared with other sutures, and this might have led to the complete absence of heart block in this series.

In conclusion, we present a technique that is easy and reliable for reinforcing the proximal anastomosis for difficult reoperations of a damaged aortic root.

\section{References}

1. Malvindi PG, Putte BP, Heijmen RH, Schepens MAAM, Morshuis WJ. Reoperations on the aortic root: experience in 46 patients. Ann Thorac Surg. 2010;89: 81-6.

2. Raanani E, Dacid TE, Dellgren G, Armstrong S, Ivanov J, Feindel C. Redo aortic root replacement: experience with 31 patients. Ann Thorac Surg. 2001;71: 1460-3.

3. Nakamura Y, Tagusari O, Seike Y, Domoto S. Inverted graft insertion technique for apicoaortic bypass. Eur J Cardiothorac Surg. 2010;38:795-7.

4. Szeto WY, Bavaria JE, Bowen FW, Geirsson A, Cornelius K, Hargrove WC, et al. Reoperative aortic root replacement in patients with previous aortic surgery. Ann Thorac Surg. 2007;84:1592-9.

5. Leyh R, Knobloch K, Hagl C, Ruhparwar A, Fischer S, Kofidis T, et al. Replacement of the aortic root for acute prosthetic valve endocarditis: prosthetic composite versus aortic allograft root replacement. J Thorac Cardiovasc Surg. 2004;127: 1416-20.

\title{
How to choose the best available homograft to reconstruct the right ventricular outflow tract
}

\author{
David Kalfa, MD, Loïc Macé, MD, Dominique Metras, MD, and Bernard Kreitmann, MD, Marseille, \\ France
}

Cryopreserved homografts are among the most widely used tools to reconstruct the right ventricular outflow tract (RVOT). Numerous risk factors for homograft degeneration related to the operation, patient, and cardiac disease are clearly established but remain unmodifiable. On the other hand, risk factors related to the homograft by itself (eg, donor, processing, storage) are not consensual and influence the fate of the reconstructed RVOT through the choice of

From the Department of Cardiac and Thoracic Surgery of the La Timone Children's Hospital, Marseille, France.

Disclosures: Authors have nothing to disclose with regard to commercial support.

Received for publication Oct 3, 2010; revisions received Dec 8, 2010; accepted for publication March 1, 2011; available ahead of print April 1, 2011.

Address for reprints: David Kalfa, MD, Marie Lannelongue Hospital, Department of Pediatric Cardiac Surgery, 133 Av De la Résistance, 92350 Le Plessis Robinson,

France (E-mail: davidkalfa@gmail.com).

J Thorac Cardiovasc Surg 2011;142:950-3

$0022-5223 / \$ 36.00$

Copyright (c) 2011 by The American Association for Thoracic Surgery

doi:10.1016/j.jtcvs.2011.03.005 the homograft made by the surgeon at the time of implantation. The objective of this study was to determine the risk factors for homograft dysfunction and failure related to the origin, characteristics, and processing of the homograft to help the surgeon to choose the best available homograft for a given patient.

\section{PATIENTS AND METHODS}

A retrospective study (1993-2009) included 222 consecutive pediatric and adult patients with implantation of a homograft for reconstruction of the RVOT. All homografts came from a local tissue bank and were cryopreserved in nitrogen vapor $\left(-2^{\circ} \mathrm{C} / \mathrm{min}\right.$ to $-5^{\circ} \mathrm{C} / \mathrm{min}$, up to $\left.-150^{\circ} \mathrm{C} / \mathrm{min}\right)$ after processing. Studied end points were homograft dysfunction and homograft failure. Homograft dysfunction was defined on echocardiographic criteria: a peak gradient of $50 \mathrm{~mm} \mathrm{Hg}$ or more or a regurgitation grade at least moderate. Serial transthoracic echographic measurements were performed at discharge and then yearly thereafter by the same in-house cardiologist whenever possible using 2.5-MHz ultrasound transducers (HewlettPackard Sonos 2500 System; Hewlett-Packard Co, Andover, Mass) or by the referring cardiologist in the remaining cases. Maximum velocities across the pulmonary valve were calculated by a continuous-wave Doppler 
TABLE 1. Characteristics of the patients and implanted homografts

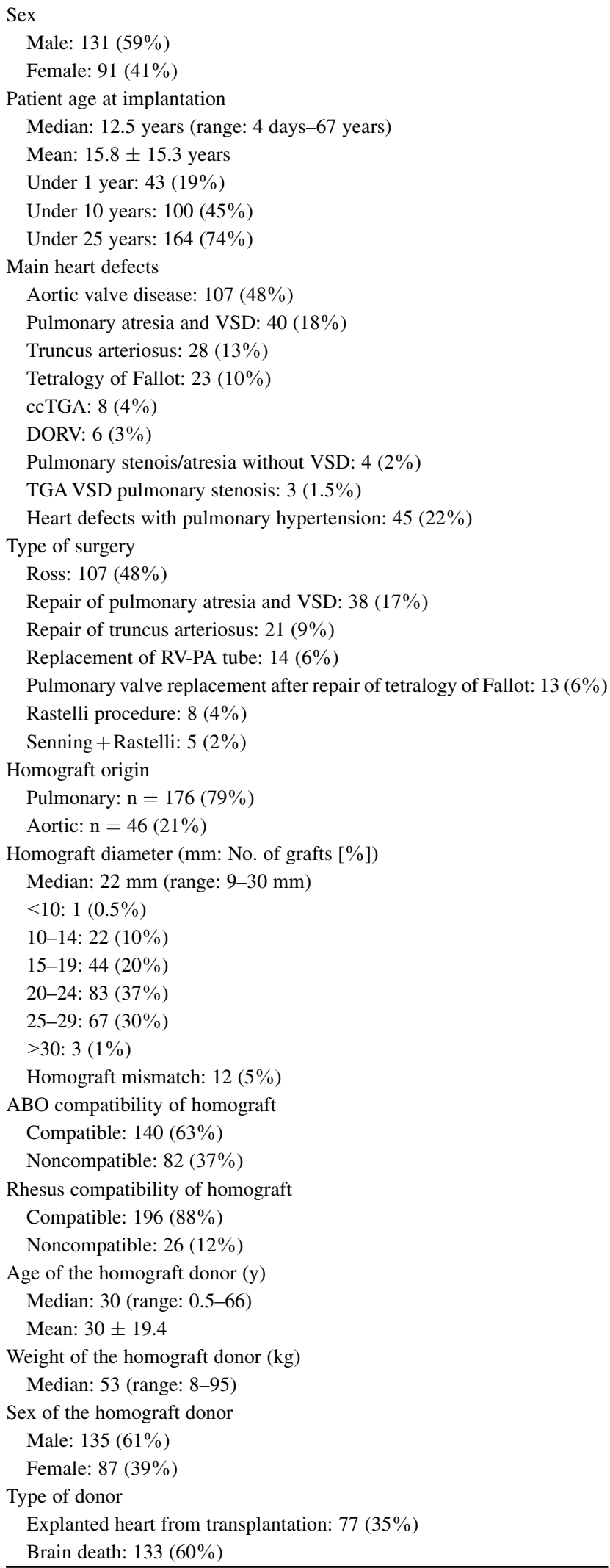

(Continued)
TABLE 1. Continued

Cadaver: $2(1 \%)$

NA: $10(5 \%)$

Main causes of death of the donor

Cerebrovascular accident: 38

Cranial trauma: 17

Polytraumatism: 12

Cerebral anoxia: 10

Meningitis: 4

Medium of conservation

RPMI (Roswell Park Memorial Institute): 197 (89\%) (before June 2007)

SCOT (MacoPharma, MACO-BIOTECH transplant): 25 (11\%) (after

June 2007)

Decontamination time (h)

Median: 12 (range: 4-18)

Mean: $10.7 \pm 5.4$

Cold ischemia time (h)

Mean: $55 \pm 26$

Storage time (mo)

Median: 14 (range: 0.5-136)

Macroscopic anomalies of the homograft

Atheroma: 5

VSD (closed before implantation): 2

Fenestrated cusp: 2

Follow-up (y)

Mean: $5.5 \pm 4.5$

Median: 4.7 (range: 0-17.9)

$V S D$, Ventricular septal defect; $c c T G A$, congenitally corrected transposition of great arteries; $D O R V$, double-outlet right ventricle; $R V-P A$, right ventricular-pulmonary arterial; homograft mismatch is defined as a diameter of the implanted homograft $<-2$ standard deviations or $>2$ standard deviations of the theoretical pulmonary annulus diameter.

imaging transducer. The Bernoulli equation was used to determine the pressure gradient. Semiquantitative assessment from grade 0 (absent) to 3 (severe) of homograft regurgitation was based on the length and width of the regurgitant jet and the distance that it reaches into the RVOT on the parasternal short-axis view. Homograft failure was defined as the requirement for homograft explantation, percutaneous balloon dilation, or percutaneous valve implantation. A reintervention or percutaneous procedure was required when right ventricular/left ventricular pressure gradient was greater than $2 / 3$ or when the homograft displayed a moderate-to-severe regurgitation. Univariate and multivariate Cox regression analysis were performed with SPSS 15.0 software (SPSS, Inc, Chicago, Ill). Adjustment factors for multivariate analysis were the age and sex of the patient, heart defect, pulmonary hypertension (defined as an echographic systolic pulmonary artery pressure $>30 \mathrm{~mm} \mathrm{Hg}$ ), type of surgery (Ross or non-Ross), period of surgery, surgeon, sternal compression of the homograft (peroperative diagnosis), and changes in the homograft conservation protocol. The study was approved by the institutional review board of the French Society of CardioVascular Surgery.

\section{RESULTS}

The characteristics of the patients and implanted homografts are presented in Table 1. Overall homograft dysfunction and failure rates were $40 \%$ and $14 \%$, respectively, with a mean follow-up of $5.5 \pm 4.5$ years. Dysfunction rates were $65 \%$ in patientsless than 1 year old at implantation $(\mathrm{n}=28 / 43), 58 \%$ in patients between 1 and 10 years old $(\mathrm{n}=33 / 57)$, and $24 \%$ in patients more than 10 years old 
TABLE 2. Significant univariate and multivariate risk factors for homograft dysfunction and failure related to the origin, characteristics, and processing of the homograft

\begin{tabular}{ll}
\hline \multicolumn{1}{c}{ Multivariate risk factors } & \\
\hline Homograft dysfunction & $P$ value \\
Homograft diameter $<22 \mathrm{~mm}$ & HR: $4.5, P<10^{-3}$ \\
Young age of the donor $<30 \mathrm{y}$ & HR: $2.3, P=.04$ \\
ABO incompatibility of the homograft & HR: $3.1, P=.003$ \\
Female sex of the donor & HR: $2.3, P=.02$ \\
Homograft failure & HR: $4.1, P=.03$ \\
Aortic origin of the homograft & HR: $6.3, P=.03$ \\
Homograft diameter $<22 \mathrm{~mm}$ & HR: $8, P=.02$ \\
Homograft mismatch & \\
\hline \multicolumn{1}{c}{ Univariate risk factors } & \\
\hline Homograft dysfunction & $P<10^{-3}$ \\
Homograft diameter $<22 \mathrm{~mm}$ & $P<10^{-3}$ \\
Young age of the donor $<30 \mathrm{y}$ & $P=.04$ \\
ABO incompatibility of the homograft & $P<10^{-3}$ \\
Interval between harvest and & \\
$\quad$ decontamination $<24 \mathrm{~h}$ & $P<10^{-3}$ \\
Decontamination time $<12 \mathrm{~h}$ & $P<10^{-3}$ \\
Cold ischemic time $<2 \mathrm{~d}$ & $P=.01$ \\
Storage time $<14$ mo & $P=.04$ \\
Female sex of the donor & $P=.002$ \\
Homograft failure & $P=.003$ \\
Aortic origin of the homograft & $P=.04$ \\
Homograft diameter $<22 \mathrm{~mm}$ & $P<10^{-3}$ \\
Homograft mismatch & $P<10^{-3}$ \\
Young age of the donor $<30 \mathrm{y}$ & \\
Interval between harvest and & \\
$\quad$ decontamination $<24 \mathrm{~h}$ & \\
Decontamination time $<12 \mathrm{~h}$ & \\
Cold ischemic time $<2 \mathrm{~d}$ & \\
\hline
\end{tabular}

Homograft mismatch is defined as a diameter of the implanted homograft $<-2$ standard deviations or $>2$ standard deviations of the theoretical pulmonary annulus diameter. Adjustment factors for multivariate Cox regression analysis were the age and sex of the patient, heart defect, pulmonary hypertension, type of surgery (Ross or nonRoss), period of surgery, surgeon, anatomic distortion of the homograft, sternal compression of the homograft, and changes in the homograft conservation protocol. $H R$, Hazard ratio.

$(\mathrm{n}=29 / 122)\left(P<10^{-3}\right)$. Failure rates were $28 \%(\mathrm{n}=12 /$ $43), 21 \%(\mathrm{n}=12 / 57)$, and $6 \%(\mathrm{n}=7 / 122)$ in these 3 populations, respectively $\left(P<10^{-3}\right)$. Dysfunction rate and failure rate in the Ross population were $27 \%(\mathrm{n}=32 / 107)$ and $6 \%(\mathrm{n}=7 / 107)$, respectively; versus $50 \%(\mathrm{n}=57 / 115)$ and $21 \%(\mathrm{n}=24 / 115)$ in the non-Ross implantation $\left(P<10^{-3}\right)$. The aortic origin of the homograft, a too small homograft $(<22 \mathrm{~mm}$ or z-score $<-2)$, a too large homograft (z-score $>2$ ), young age $(<30$ years), and female sex of the donor and an $\mathrm{ABO}$ incompatible homograft significantly alter the outcomes of the homograft in the multivariate analysis (Table 2). Short decontamination, ischemia, and storage times are significantly associated with increased homograft dysfunction and failure in the univariate analysis (Table 2).

\section{DISCUSSION}

The use of a pulmonary homograft with a diameter comprised between -2 and $+2 \mathrm{z}$-score of theoretical pulmonary annulus diameter seems to be the basal requirement for an adapted reconstruction of the RVOT by a cryopreserved homograft. Aortic homografts and smaller homografts have frequently been found to be associated with valve failure in the literature, in relation with a higher risk of calcifications for aortic homografts and the absence of growth potential. ${ }^{1}$

Our multivariate analysis also showed that oversizing a homograft with a $z$-score of more than +2 actually decreased the homograft survival, as previously described in the literature. This risk factor for homograft failure seems to us more related to altered flow patterns than to a mechanical compression of the homograft. Indeed, the cases of sternal compression of the homograft that we noticed during the operation at the time of chest closure did not occur in the patients with implantation of a larger homograft (z-score $>2$ ). The discrepancy between a too large homograft and the relative "too small" right ventricle and pulmonary arteries could lead to a turbulent blood flow through the oversized homograft, causing the increase of pulmonary flow velocity that Moidl and associates ${ }^{2}$ described in their population of right-sided oversized homografts. Such an altered turbulent flow within the oversized homograft might at least partially explain the increased risk for homograft failure after implantation of such an oversized homograft.

We also advocate choosing homografts coming from a male donor older than 30 years, if available. Initially, the vast majority of studies identified an increasing homograft donor age ( $>50,55$, or 65 years depending on the series) as a risk factor. However, more recent studies reported a significant association with young donor age $\left(<30\right.$ years or $<5$ years $\left.^{3}\right)$, as we also demonstrated in our multivariate analysis. Cryopreserved homografts from younger donors might be more antigenic owing to persistence of histocompatibility antigen expression or cell viability and thus more subject to immunologic damage. ${ }^{4}$ Nevertheless, there are currently no biological or immunologic data allowing us to state that a younger donor-derived homograft when treated identically to an adult donor-derived one displays more antigens on its surface.

Homograft $\mathrm{ABO}$ incompatibility as a possible major risk factor resulting in an important immunologic response has been debated extensively. ${ }^{5}$ Our multivariate analysis supports this hypothesis and could lead the surgeon to prefer choosing available ABO-compatible conduits.

The role of decontamination, ischemia, and storage times in altered outcomes of homograft, on the basis of an excessive inflammatory reaction, is still largely controversial. ${ }^{4}$ According to our study, longer processing times (decontamination time $>12$ hours, cold ischemic time $>2$ days) could be preferred in the choice of the homograft but seem to have a smaller impact on the homograft outcome. 
Other suspected homograft-related factors such as Rhesus group compatibility, type of donor (cardiac transplant recipients, heart-beating donor), cause of donor death, and type of conservation medium were in fact not relevant in the statistical analysis and thus should probably not be considered.

To conclude, the cardiac surgeon who has to reconstruct an RVOT with a homograft in a Ross or a non-Ross patient could optimize his choice by opting, if available, for ABOcompatible pulmonary homografts with a $-2<\mathrm{z}$-score diameter $<2$, coming from a male donor older than 30 years, with longer processing times.

A prospective randomized trial should be performed to confirm these conclusions.

\section{References}

1. Selamet Tierney ES, Gersony WM, Altmann K, Solowiejczyk DE Bevilacqua LM, Khan C, et al. Pulmonary position cryopreserved homografts: durability in pediatric Ross and non-Ross patients. J Thorac Cardiovasc Surg. 2005; 130:282-6.

2. Moidl R, Simon P, Kupilik N, Chevtchik O, Heinrich N, Moritz A, et al. Increased pulmonary flow velocities in oversized homografts in patients after the Ross procedure. Eur J Cardiothorac Surg. 1997;12:569-72.

3. Niwaya K, Knott-Craig CJ, Lane MM, Chandrasekaren K, Overholt ED, Elkins RC. Cryopreserved homograft valves in the pulmonary position: risk analysis for intermediate-term failure. J Thorac Cardiovasc Surg. 1999;117:141-6.

4. Baskett RJ, Nanton MA, Warren AE, Ross DB. Human leukocyte antigen-DR and ABO mismatch are associated with accelerated homograft valve failure in children: implications for therapeutic interventions. J Thorac Cardiovasc Surg. 2003; 126:232-9.

5. Christenson JT, Vala D, Sierra J, Beghetti M, Kalangos A. Blood group incompatibility and accelerated homograft fibrocalcifications. J Thorac Cardiovasc Surg 2004; $127: 242-50$ 